\title{
Aortic regurgitation in seropositive juvenile arthritis
}

\author{
A. M. LEAK, ${ }^{1}$ M. W. MILLAR-CRAIG, ${ }^{2}$ AND BARBARA M. ANSELL \\ From the ${ }^{1}$ Juvenile Rheumatism Unit, Canadian Red Cross Memorial Hospital, Taplow, and the ${ }^{2}$ Cardiology \\ Department, Northwick Park Hospital, Harrow, Middlesex
}

Summary Seropositive juvenile chronic arthritis is a relatively uncommon form of childhood arthritis, but it often causes severe destruction of joints associated with considerable functional disability. During the last 7 years lone aortic regurgitation has been seen to develop in 4 such patients and pursue a particularly aggressive course. Sudden deterioration occurred in 2, 1 of whom required urgent aortic valve replacement and 1 died while awaiting assessment. Because of this it is important to include regular cardiac appraisal as part of the routine assessment in seropositive juvenile arthritis.

Seropositive disease accounts for somewhat less than $10 \%$ of all chronic arthritis beginning under 16 years of age. The onset is usually about the age of 10 or 11 , and girls are affected much more commonly than boys. A particular feature of this type of disease is the persistence of activity and the very rapid destruction of joints. Elbow nodules are seen in only about a fifth of the cases, but when they do occur they have a typical rheumatoid histology. ${ }^{1}$ The purpose of this report is to draw attention to the

Accepted for publication 1 August 1980

Correspondence to Dr B. M. Ansell, Juvenile Rheumatism Unit, Canadian Red Cross Memorial Hospital, Taplow, Maidenhead, Berks SL6 0HN. relatively rapid development of severe aortic incompetence in 4 young patients.

\section{Case reports}

During the past 7 years aortic regurgitation has been observed in 4 patients, all girls. The first will be discussed in detail and the others summarised (Table 1).

\section{CASE 1}

This girl (Fig. 1) developed polyarthritis at the age of $9 \frac{1}{2}$ in November 1975. On her referral to Taplow in September 1975 the features noted were symmetrical polyarticular involvement with marked soft tissue swelling, anaemia, high erythrocyte Female Born 28.8.65 Onset March 1975

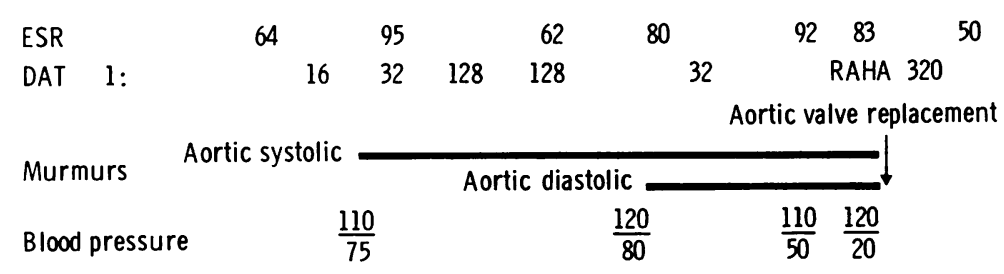

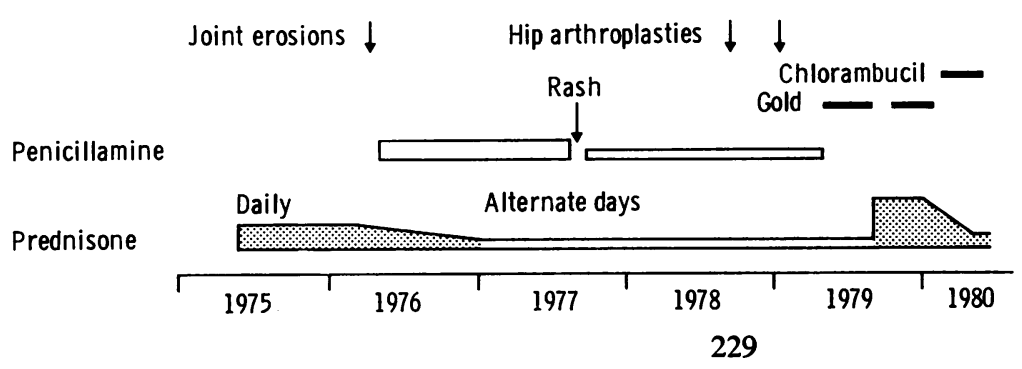

Fig. 1 Course of case 1. 
sedimentation rate, and positive IgM rheumatoid factor test. Despite early treatment with aspirin, indomethacin, and prednisolone, disease activity persisted and she quickly developed joint erosions (Fig. 2a). Penicillamine was therefore begun in March 1976. This drug was continued over a period of 3 years, though the dosage had to be reduced after 16 months owing to the development of a rash. Her erythrocyte sedimentation rate and rheumatoid factor concentration remained high, and the disease pursued a rapidly destructive course (Fig. 2b) with involvement of many joints. An ejection systolic murmur had been noted in 1976, but when she was being assessed for hip arthroplasties in February 1978 the early diastolic murmur of aortic regurgitation was first heard. At that time her electrocardiogram and chest $x$-ray were normal. She underwent left total hip replacement in August 1978 and right

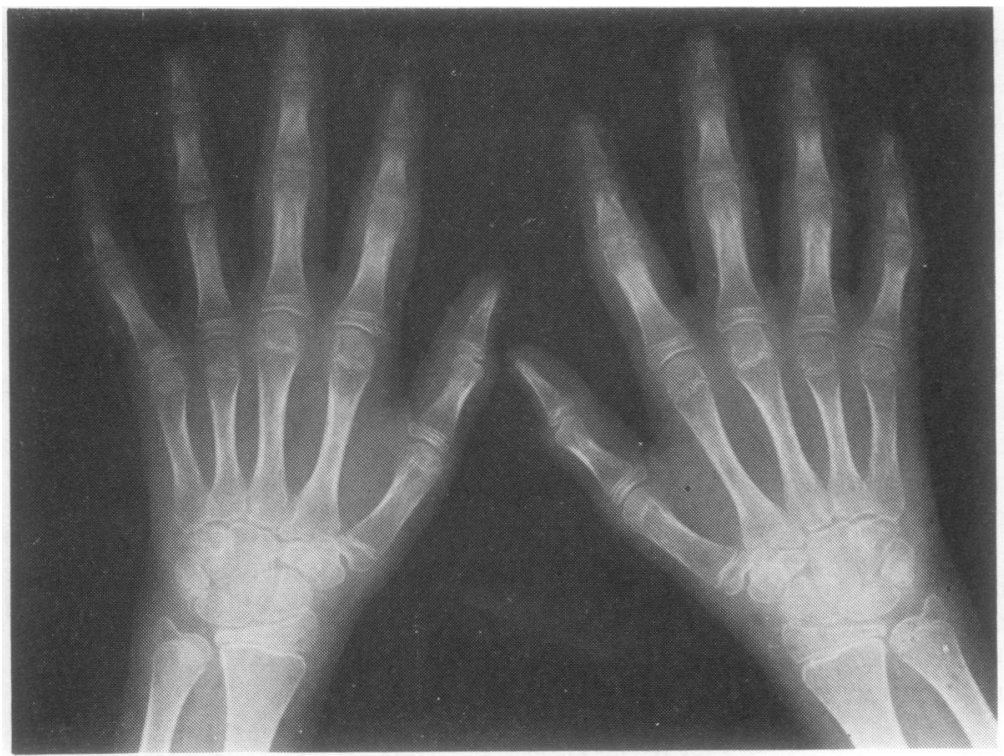

(a)

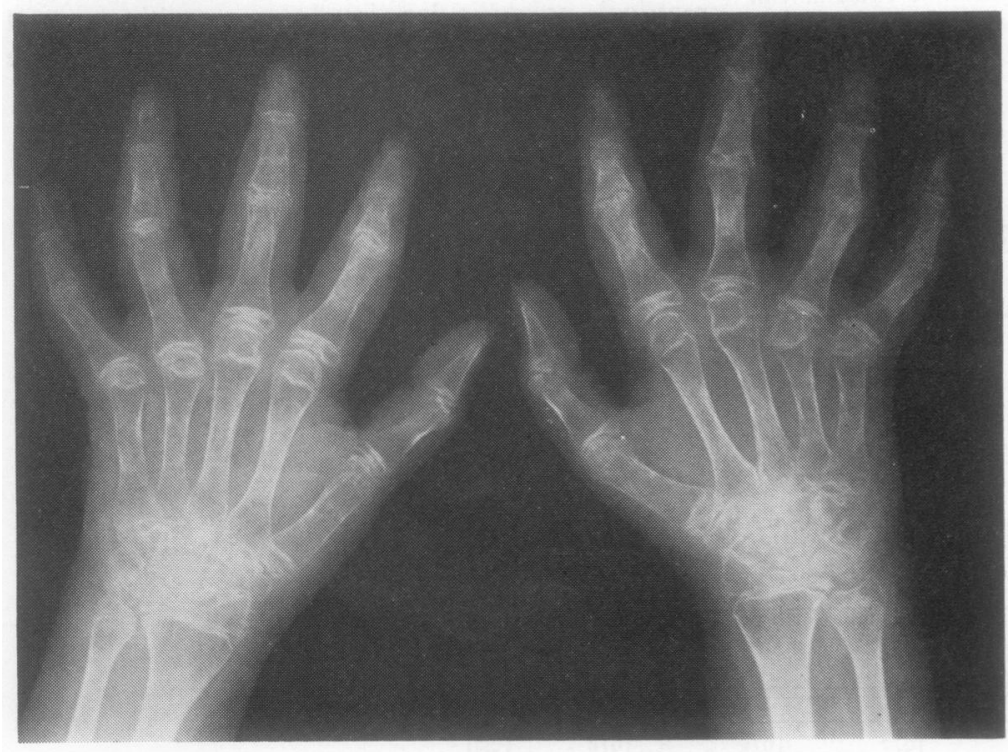

(b)
Fig. 2a Hand x-ray March 1976 one year from onset. b Hand x-ray Nov. 1978 showing marked progression of erosions. 
total hip replacement in January 1979 without complication.

Two months after the latter operation she had her first bout of chest pain. Initially a diagnosis of

Table 1 Summary of cases

\begin{tabular}{lllll}
\hline & \multicolumn{1}{l}{ Case } & & & \\
\cline { 2 - 5 } & $I$ & 2 & 3 & 4 \\
\hline $\begin{array}{c}\text { Age at onset of } \\
\text { arthritis (years) }\end{array}$ & 9 & 10 & 8 & 8 \\
$\begin{array}{c}\text { Age systolic } \\
\text { murmur heard } \\
\text { (years) }\end{array}$ & 10 & 11 & 14 & 17 \\
$\begin{array}{c}\text { Age diastolic } \\
\text { murmur heard } \\
\text { (years) } \\
\begin{array}{c}\text { Worsening } \\
\text { symptoms } \\
\text { (months) }\end{array}\end{array}$ & 12 & 16 & 15 & 18 \\
$\begin{array}{c}\text { Outcome 1980 } \\
\begin{array}{c}\text { Aortic valve } \\
\text { replacement }\end{array}\end{array}$ & $\begin{array}{c}\text { Aortic valve } \\
\text { replacement }\end{array}$ & $\begin{array}{c}6 \\
\text { Death }\end{array}$ & $\begin{array}{l}\text { Nil } \\
\text { Moderate } \\
\text { aortic } \\
\text { regurgit- } \\
\text { ation }\end{array}$ \\
\hline
\end{tabular}

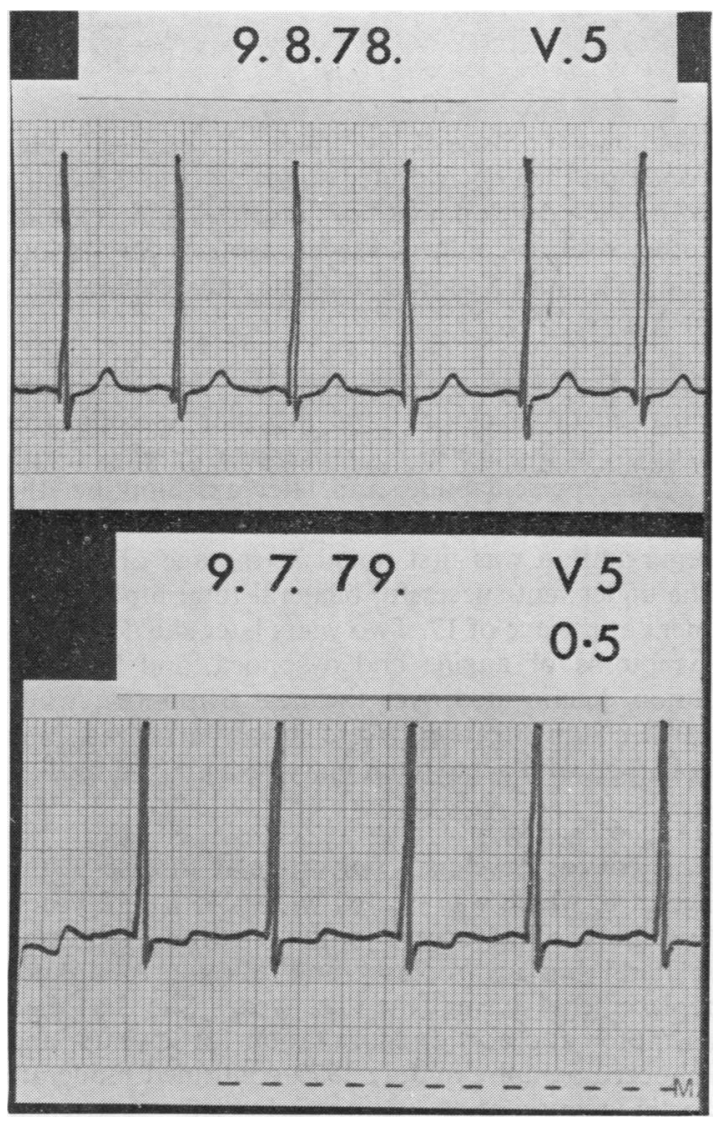

Fig. 3 Lead V5 in 1978 is compared with the same lead taken at $\frac{1}{2}$ voltage in 1979 when it may be noted that there is marked left ventricular hypertrophy. pulmonary embolism was considered, but this was not confirmed. Over the next 3 months she had increasingly frequent attacks of chest pain associated with dyspnoea. Her pulse became collapsing in nature with a widening pulse pressure. There was clinical and electrocardiographic evidence of left ventricular hypertrophy (Fig. 3). Chest $x$-ray showed a rapid increase in cardiac size (Figs. 4a, b, c). Echocardiography (July 1979) showed left ventricular dilatation, a $6 \mathrm{~mm}$ pericardial effusion, and diastolic fluttering of the anterior cusp of the mitral valve, characteristic of aortic incompetence. Angiography showed left ventricular enlargement with a normal mitral valve and gross aortic regurgitation, which was confirmed at cardiac catheterisation with an aortic pressure of $103 / 38 \mathrm{mmHg}$.

Five months from the onset of chest pain she developed acute pulmonary oedema, requiring emergency aortic valve replacement in August 1979. At operation the aortic valve was grossly thickened with very active granulomatous tissue growing into the valve itself. Histology showed that the architecture of the valve had been completely destroyed by multiple necrobiotic foci with the typical features of rheumatoid granulomata. There was also an active pericarditis with $300 \mathrm{ml}$ of free fluid. She made a good postoperative recovery with diminution of cardiac size on her chest $x$-ray (Fig. 4d).

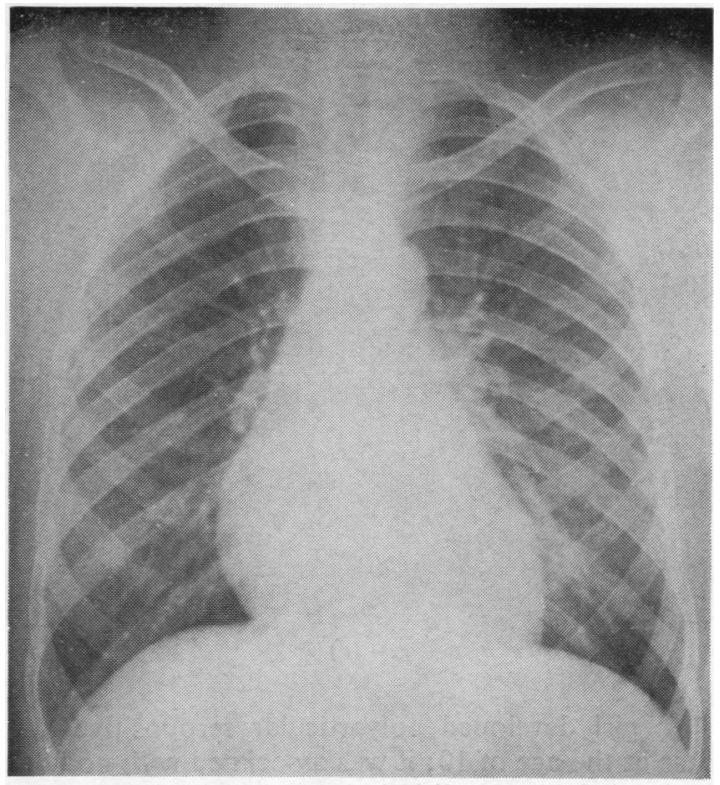

(a)

Fig. 4 Chest x-ray. a January 1979, b April 1979, c July 1979, all showing the rapidly progressive cardiomegaly; d September 1979 showing the improvement 4 weeks postoperatively. 


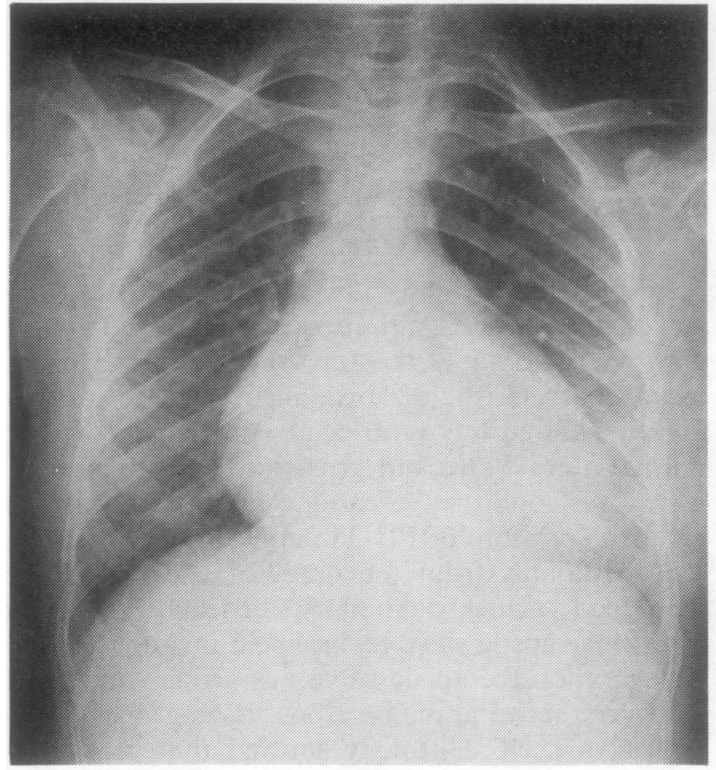

(b)

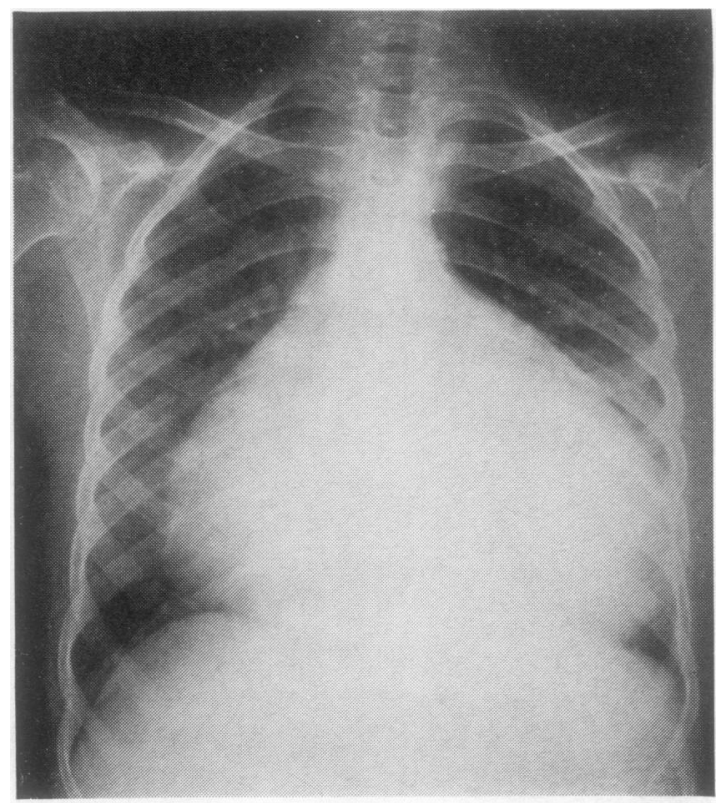

(c)

CASE 2

This girl developed polyarticular seropositive disease at the age of 10 ; it was associated with nodules and nail-fold vasculitic lesions. An ejection systolic murmur was first heard at the age of 11 when she had a bout of chest pain thought to be due to pericarditis. Aortic regurgitation was established 5 years later and remained mild over the next 4 years,

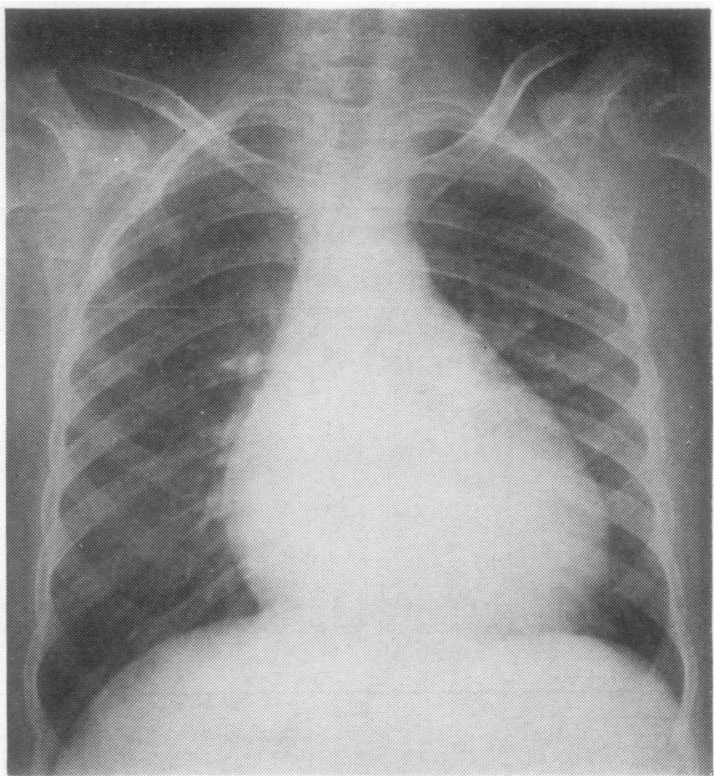

(d)

with only occasional dyspnoea on exertion. Her condition then deteriorated suddenly over 2 months with the development of angina, and cardiac catheterisation confirmed severe aortic regurgitation. She underwent a successful aortic valve replacement in August 1976.

\section{CASE 3}

This girl developed polyarticular seropositive arthritis at the age of 8 , and despite treatment with steroids, penicillamine, and later azathioprine, the disease ran a severe destructive course. Aortic regurgitation was first noted at the age of 15 , but she underwent successful bilateral total hip replacement at the age of 17. Two years later she developed symptoms of angina and dyspnoea, and her condition deteriorated over the next 6 months; while cardiac investigations were being arranged, she collapsed with acute pulmonary oedema and died.

\section{CASE 4}

This patient developed polyarticular disease at the age of 8 , which was treated with gold for 12 years, but she has had severe joint destruction requiring bilateral hip arthroplasty and a right total knee replacement during the last year. She has had asymptomatic aortic regurgitation for 2 years, and echocardiography in July 1979 confirmed moderate aortic regurgitation with early left ventricular dilatation. She is being carefully followed up as an outpatient, with serial assessment of left ventricular size using echocardiography and chest radiography. 
All these 4 girls persistently had high titres of IgM rheumatoid factor associated with a severe destructive arthropathy requiring major joint replacement. Three had subcutaneous nodules, and 1 vasculitis, but none had episcleritis. They had all been treated with either gold or penicillamine for several years, and 3 out of 4 had had long-term steroid therapy. In each case a systolic murmur was heard for some years before the development of aortic incompetence. None had had acute rheumatic fever as defined by the Duckett-Jones criteria. ${ }^{2}$ All were assessed cardiologically and 3 of them had full investigations as detailed in case 1; none had any evidence of mitral valve involvement. Surgical intervention was required in 2 cases owing to sudden deterioration in left ventricular function. At this time 2 of the patients had pericarditis as well as aortic valvular disease and there was no aortic root dilatation. At no time had there been evidence of infective endocarditis.

\section{Discussion}

The commonest cardiac complication in juvenile arthritis is pericarditis, which may be diagnosed clinically in $7 \%$ of all cases, ${ }^{3}$ but is more frequently detected by echocardiography, ${ }^{4}$ and has been found in $45 \%$ of cases at necropsy. ${ }^{3}$ It is most common in those children with systemic illness, who are, of course, negative for IgM rheumatoid factor. Myocarditis has also been reported in this group. ${ }^{5}$ The decline in the incidence of rheumatic fever has emphasised the importance of considering other causes of valvular disease in patients with joint symptoms. In a necropsy study of 400 cases of functionally severe valvular disease it was concluded that when aortic incompetence occurs without mitral valve disease it is not of rheumatic origin. ${ }^{6}$

The concept of rheumatoid heart disease was postulated in 1960 by Bywaters ${ }^{7}$ and has gradually found acceptance. ${ }^{8}$ Both specific granulomatous nodules and nonspecific lesions have been found in the hearts of adults with rheumatoid arthritis. ${ }^{8}$ Involvement of the pericardium, myocardium, and endocardium has been well documented, ${ }^{8-11}$ but the lesions have generally been thought to be haemodynamically unimportant. However, nodular deformity of a valve is known to lead to its incompetence, ${ }^{10}$ and cardiovascular disease accounts for $25 \%$ of all deaths due to rheumatoid disease. ${ }^{8}$ Seropositive juvenile arthritis resembles the adult disease, and when valvular lesions occur in adult rheumatoid arthritis the aortic valve is the one most commonly affected. However, coexistent mitral valve disease has been found in $63.6 \%$ of cases. ${ }^{12}$ Post-rheumatic fever aortic regurgitation usually remains mild for many years, and even severe regurgitation may be tolerated for a decade or more without symptoms. ${ }^{13}$ This is in sharp contrast to some recently reported cases of rheumatoid arthritis and aortic regurgitation causing left ventricular dysfunction and requiring aortic valve replacement. ${ }^{8}$ These patients show similarities to our juveniles. In 3 of our cases valvular dysfunction lasted less than 4 years before sudden deterioration: 2 required aortic valve replacement and 1 died while awaiting assessment. Histology of the 2 removed valves showed destruction of the normal architecture by rheumatoid granulation tissue. Therapy with gold and penicillamine is known to cause dissolution of nodules. If healing of endocardial granulomata occurs, retraction of the valve cusps could cause a deterioration in function. While the second of our patients was on penicillamine, her elbow nodules disappeared at a time when her cardiac function worsened. However, in the first case active nodular lesions were obviously responsible for the destruction of her valve, leading to severe incompetence. It is suggested that regular cardiac assessment should be carried out in such patients to look for the development of an aortic diastolic murmur. If one is found it should be watched closely, since the natural history of aortic regurgitation in seropositive juvenile arthritis appears to be particularly short.

Repeated noninvasive assessment can be made by echocardiography, with which it has been shown that measurement of the left ventricular diastolic dimension and fractional shortening are useful in predicting deterioration and may be helpful when considering the timing of surgery. ${ }^{14} 15$ The development of left ventricular dysfunction is an indication for urgent surgical referral, because rapid deterioration with the development of angina in a young patient is associated with an increased risk of sudden death. ${ }^{13}$

We thank Dr J. Raftery, Northwick Park Hospital, Harrow, and Dr R. C. Radley Smith and Mr M. H. Yacoub, Harefield Hospital, for their assistance in the investigation and management of these patients.

\section{References}

1 Ansell B M. Heberden Oration, 1977. Chronic arthritis in childhood. Ann Rheum Dis 1978; 37: 107-20.

2 Stollerman G H, Markowitz M, Taranta A, Wannamaker L W, Whittemore R. Report of the Jones criteria (revised) for guidance in the diagnosis of rheumatic fever. Circulation 1965 ; 32: 664-8.

3 Lietman P S, Bywaters E G L. Pericarditis in juvenile rheumatoid arthritis. Pediatrics 1963; 32: 855-60.

4 Bernstein N, Takahashi M, Hanson V. Cardiac involvement in juvenile rheumatoid arthritis. $J$ Pediatr 1974; 85: 313-7. 
5 Miller J J, French J W. Myocarditis in juvenile rheumatoid arthritis. Am J Dis Child 1977; 131 : 205-209.

6 Roberts W J. Anatomically isolated aortic valvular disease. The case against its being of rheumatic etiology. Am J Med 1970; 49: 151-9.

7 Bywaters E G L. The relation between heart and joint disease. Br Heart J 1950; 12: 101-31.

8 Iveson J M I, Pomerance A. Cardiac involvement in rheumatoid disease. Clin Rheum Dis 1977; 3: 467-500.

9 Clark W S, Bauer W. Cardiac changes in rheumatoid arthritis. Ann Rheum Dis 1948; 7: 39-40.

10 Fassbender H G. In: Loewi G, trans. Pathology of Rheumatic Diseases. Springer, 1975: 149-57.

11 Prakash R, Atassi A, Poske R, Rosen K M. Prevalence of pericardial effusion and mitral valve involvement in patients with rheumatoid arthritis without cardiac symptoms. An echocardiographic evaluation. $N$ Engl $J$ Med 1973; 289: 597-600.

12 Iveson J M I, Thadani U, Ionescu M, Wright V. Aortic valve incompetence and replacement in rheumatoid arthritis. Ann Rheum Dis 1975; 34: 312-20.

13 Reichek N, Shelburne J C, Perloff J K. Clinical aspects of rheumatic valvular disease: aortic regurgitation. Prog Cardiovasc Dis 1973; 15: 518-23.

14 Henry W L, Bonow R O, Borer J A, et al. Observations on the optimum time for operative intervention for aortic regurgitation. 1. Evaluation of the results of aortic valve replacement in symptomatic patients. Circulation 1980; 61: 471-83.

15 O'Rourke R A, Crawford M H. Editorial: Timing of valve replacement in patients with chronic aortic regurgitation. Circulation 1980; 61 : 493-5. 